\title{
Autobiografía y canon literario: historia de un desencuentro
}

\author{
Autobiografia e cânone literário: história de um desencontro
}

Anna Caballé

Universidade de Barcelona - Barcelona - Espanha

$\diamond$

\begin{abstract}
Resumen: El artículo plantea los motivos por los que, a lo largo de la historiografía literaria española, los géneros autobiográficos han mantenido un papel secundario y opaco a pesar de la riqueza de los textos. Comparar la evolución del género con la ocurrida en otros ámbitos literarios se ha demostrado poco operativo, dada la especificidad de la cultura española. Ha llegado el momento de revisar la periodización de la autobiografía en España, de acuerdo con los acontecimientos históricos que la marcaron y que permiten explicar su ascenso como su decadencia.
\end{abstract}

Palabras clave: Autobiografía; Periodización; Canon literario

Resumo: $\mathrm{O}$ artigo discute as razões pelas quais, ao longo da historiografia literária espanhola, os gêneros autobiográficos tiveram um papel secundário e opaco apesar da riqueza dos textos. Comparar a evolução do gênero com a de outros âmbitos literários têm se revelado pouco operacional, dada a especificidade da cultura espanhola. É chegado o momento de se rever a periodização da autobiografia na Espanha, de acordo com os acontecimentos históricos que a marcaram e que explicam tanto sua ascensão quanto seu declínio.

Palavras-chave: Autobiografia; Periodização; Cânone literário

\section{La autobiografía española vs. la autobiografía francesa}

En 1877, un historiador francés, Philarète Chasles, con un conocimiento aproximado de la cultura española, sentenció la escasa inclinación de los españoles a los géneros autobiográficos, sugiriendo posibles interpretaciones histórico-morales. A la pregunta de "Pourquoi les espagnols n'ont pas écrit pas de mémoires", respondía: "Les Espagnols ont écrit peu de mémoires ... Une fierté silencieuse enveloppe leur vie et leur mort" [Los españoles han escrito pocas memorias. Un orgullo silencioso envuelve su vida y su muerte]. Y, un poco más adelante, Chasles ahondaba en nuestro supuesto vacío... "En Espagne les gens de lettres eux-mèmes et les artistes, assez enclins a la vanité, chez tous les peuples, ne son contentés de l'orgueil; point de Benvenuto Cellini ni de Jean-Jacques rousseau invitant le monde à écouter sa confession personelle"1.

Los españoles pues se contentaban con su orgullo y prescindían del relato que les permitiría desvelar los secretos y motivaciones de su carácter. No hay duda de que el juicio de Chasles es un punto altanero y desdeñoso, pero solo quiero subrayar que sus juicios encabezan el capítulo dedicado a los escritos justificativos de Antonio
Pérez, secretario de Felipe II y un hombre que cayó en desgracia ante el monarca por cuestiones que ahora nos son ajenas a nuestro propósito y razón por la cual se vio obligado a justificarse ${ }^{2}$. "Todos tomaban la espada y ninguno la pluma" había dicho ya Feijoo más de cien años atrás ${ }^{3}$. Es decir que la idea venía arrastrándose desde el siglo XVIII, tal vez de antes. El mismo Feijoo había matizado su propia idea al verla repetida en otras fuentes: "El caso es que el vulgo de los extranjeros atribuye en nosotros a defecto de habilidad lo que sólo es falta de aplicación"4.

En todo caso, los escritores europeos juzgaron con severidad las letras españolas a lo largo del siglo XVIII: le reprochaban los excesos herméticos del Barroco y condenaban una supuesta falta de atención al testimonio de sí que hacía de España un país supuestamente sin reflejo. Lo importante para el propósito de esta conferencia es señalar que mientras las ideas sobre el Barroco quedarían corregidas, en parte, por la historiografía romántica y

\footnotetext{
1 En la France, l'Espagne et l'Italie au XVII siècle, Paris, 1877, p. 213. Disponible en internet.

2 Cartas para diversas personas después de su salida de España (Paris, 1598) y Obras y relaciones (Ginebra, 1654).

3 "Glorias de España", en su Teatro crítico universal (IV, 13).

4 Ibid.
} 
su revisión de la dramaturgia del Siglo de Oro (de Lope de Vega, Agustín Moreto, Ruiz de Alarcón y sobre todo de Calderón de la Barca reivindicado por los hermanos Schlegel en 1811), las ideas vinculadas a la supuesta "falta de inclinación" del español en relación a la escritura auto/biográfica, seguirían su marcha hasta un pasado en realidad no muy lejano. Es muy interesante observar el funcionamiento de las inercias intelectuales. Pueden reproducir hasta el infinito el mismo tópico, el mismo lugar común, sin que nadie lo ponga en duda, aunque, como siempre ocurre, el tópico lleve su parte de razón.

Un escritor romántico, Patricio de la Escosura, amigo de Espronceda, al iniciar sus Memorias de un coronel retirado, en 1868, decía lo siguiente:

Es un hecho universalmente reconocido, y también deplorado por cuantos en España se ocupan en investigaciones históricas que entre nosotros escasean, tanto como entre los franceses abundan, los libros que se llaman Memorias.

Pero él mismo acababa de escribir las suyas al asegurar que tanto escaseaban, aunque eso no le hiciera reflexionar sobre la falta de coherencia que encerraba su propio juicio. Es decir que con la mano derecha hacía lo que su mano izquierda negaba. Lo mismo ocurriría con el erudito Jorge Campos, cuando aprovechaba su introducción a una nueva edición de las Memorias del historiador, también romántico, Antonio Alcalá Galiano (1886), para poner, una vez más, el dedo en la llaga:

España, que ha producido, en tantas ocasiones colectivas de trascendencia histórica, hombres cuya vida es sorprendente por su riqueza aventurera, rara vez conserva testimonios en que el héroe nos ofrezca su personal visión de los acontecimientos en que ha tomado parte ${ }^{5}$.

Lo dice pues al hilo de otro texto memorialístico que se lee como excepcional en medio del supuesto desierto. Por su parte, la tradición intelectual hispanoamericana asumiría ese déficit hispánico, repitiéndolo en términos muy parecidos. Veamos el comentario que hace en 1930, un poeta mexicano, Jaime Torres Bodet:

España se ha derramado por el mundo. Según el sesgo de una abundancia tan desigual, que la vida resulta, en las latitudes de su heroísmo una dádiva que casi no agradece. Que, por lo menos, nadie comenta. ¿Dónde están - si no- los diarios, los manuscritos secretos, las colecciones iconográficas- las cartas, los relatos y las reliquias de muchos de los personajes que han modelado desde la celda laica de la patria española el camino y las formas de la Historia Universal? Frente a la multiplicidad de las crónicas, las confesiones y los diálogos epistolares de que se enorgullecen otros museos, asusta la soledad en que cada noble existencia española ha querido desarrollar su tragedia. ${ }^{6}$

Es un comentario formulado precisamente por los mismos años en los que el filósofo Ortega y Gasset luchaba desde diversas plataformas culturales para cambiar ese orden de cosas: fundó la Revista de Occidente en la que se concedía una importancia especial a la literatura auto/biográfica en artículos y reseñas, inspiró la colección "Vidas españolas e hispanoamericanas" y centró su pensamiento en la defensa de la concepción diltheyana de la vida como eje central de la filosofía, idea expuesta a lo largo de su dispersa obra. Bueno, pues es el mismo Ortega y Gasset quien escribiendo a propósito de la publicación de las memorias escritas por la marquesa de La-Tour-du- Pin, comentaba, especulando sobre las posibles causas de nuestra dejadez historiográfica, que en España no se escribían libros de memorias porque los españoles concebían la vida como "un permanente dolor de muelas". Es decir que carecíamos como pueblo de la sensualidad hacia el pasado que sí era característica de otras culturas limítrofes. Y de nuevo surgía la condena: "Francia es el país donde se han escrito siempre más memorias; España, el país en que menos"7.

Hay que advertir que cuando Ortega y Gasset en los años 30 del siglo XX utilizaba el término memorias este disfrutaba todavía de una formidable riqueza semántica (que después perdería): incluía en él los textos que daban cuenta de una vida vivida, los que se sumergían en los arcanos del poder y de la política y aquellos textos más evanescentes que aspiraban a reflejar la dispersión de la vida mundana, agrupando así un corpus de obras muy diverso. Unos años después ese corpus se escindiría, emergería la autobiografía como un género más democrático y transversal, mientras que las memorias se verían como la expresión de un mundo de clases donde solo el personaje célebre - noble, político o triunfador merece ser el sujeto del testimonio biográfico.

En todo caso, es una opinión que la encontramos por doquier. Que hizo suya la generación del 98. Por ejemplo, Unamuno, tan interesado siempre en la autobiografía, pensaría en voz alta al buscar posibles explicaciones: "Acaso se deba a la monotonía y poco saliente de nuestra vida ordinaria, acaso a lo flacos de memoria que somos, ya individual ya colectivamente,

\footnotetext{
5 En BAE, 83-84, Madrid, 1955.

6 En "Vidas españolas del siglo XIX", Revista de Occidente (1930), XXVII, p. 281-293.

7 En "Sobre unas memorias", vol. III de las O.C., Revista de Occidente, 1957 , p. 588-592.
} 
acaso también al poco, al poquísimo interés que aquí despierta el hombre". ${ }^{8}$

Son tantos, en fin, los autores españoles de todas las épocas que se suman a esa doxa historiográfica que resulta sumamente laborioso reconstruir lo que llamé en mi tesis "el tópico de la escasa afición". El gran maestro Américo Castro (por cierto, nacido en Brasil), dejándose llevar por el entusiasmo, llegó a mencionar la "agrafía" del español y dudaba de si era "una falla de la inteligencia y de la voluntad, o un modo de ser gracias al cual podían surgir, sin embargo, valores que no serían posibles de otra manera". ${ }^{9}$ Nos enfrentamos pues a una lluvia de (auto)descalificaciones acerca del papel desempeñado por la cultura española en el desarrollo de la literatura memorialística, juicio que choca con el frecuente "chauvinisme" observable en otras culturas europeas. Sabido es que la autobiografía, como la biografía, son géneros británicos y así lo reivindican... $\mathrm{O}$ bien que los franceses son los más dotados al respecto. El admirado crítico Philippe Lejeune iniciaba su estudio L'autobiographie en France con una pregunta complaciente: “¿Están dotados los franceses para la autobiografía?" y respondía a continuación, satisfecho: "Eso parece indiscutible". ${ }^{10}$

De modo que los españoles hemos sido los primeros a la hora de advertir y dar por hecha nuestra inferioridad en el dominio de la autobiografía, y en lamentar su supuesta ausencia en nuestra tradición cultural. De más está decir que pertrechada con esta argumentación su inclusión en el canon de la literatura española resultaba inviable: si incluso se negaba su existencia, mal podía concebirse que algunos libros de memorias tuvieran un alcance ejemplar o paradigmático y obraran como modelos de lengua o de pensamiento. Si a este reparo añadimos el sostenido por los adictos a ver la literatura como un recinto sagrado en el que sólo pueden habitar las formas más puras, la autobiografía, forma impura e irregular por excelencia, siempre a caballo entre la historia y la literatura, entre la vida y el arte, entre la poiesis y la mimesis, se vio desplazada a un lugar subalterno y absolutamente marginal. Por poner un ejemplo, las Memorias del poeta romántico José Zorrilla (Recuerdos del tiempo viejo) son,

\footnotetext{
8 Cfr. En torno al casticismo (1895). "[E]ntre todos los escritores prefiero los más personales. Me encantan las autobiografías, las confesiones, las memorias, los epistolarios, San Agustín, Pascal, Rousseau, Montaigne, Amiel ... Son legión" leemos en su artículo "Sobre mí mismo", en Los Lunes de El Imparcial, 24/11/1913.

9 Citado por Juan Marichal, en "La voluntad de estilo", Revista de Occidente, 1971, pág. 190

${ }^{10}$ Armand Colin, 1971.

11 Algunos de esos comentarios desdeñosos a los que me refiero están recogidos en el capítulo IV de mi libro Una breve historia de la misoginia, Lumen, 2006.

12 En Las reglas del arte. Génesis y estructura del campo literario, Anagrama, 1994, p. 289 y ss.
}

a día de hoy, el texto más moderno y atractivo de su autor, el que mejor ha resistido el paso del tiempo, aunque ningún manual de literatura así lo reconozca, reduciéndose a considerar más o menos maquinalmente su obra poética y dramática y prescindiendo de un texto excepcionalmente confesional y de un gran valor humano. Si a estos graves reparos añadimos una última posibilidad, y es que el autor de las memorias pudiera ser una mujer, tenemos un ejemplo de la tormenta perfecta. Me remito a un texto cuya recepción crítica he estudiado en otras ocasiones: la publicación de las Memorias de Emilia Pardo Bazán, en 1884, aparecidas como prólogo a su novela Los pazos de Ulloa. Con ese texto puede decirse que tocamos hueso pues a las tradicionales "resistencias a la autobiografía", por utilizar la expresión utilizada por Philippe Lejeune, se sumaba la incompatibilidad absoluta con que en el siglo XIX se concebía el binomio mujer - cultura (o mujer - política, otra forma de decirlo) hasta el punto de considerarse la expresión memorialismo femenino como un oxímoron intolerable. Se comprende que doña Emilia, una mujer cuya inteligencia era puro músculo en ejercicio aspirara con sus memorias a integrarse en el conjunto de novelistas de su misma generación que gozaban en 1884 del reconocimiento unánime (Pereda, Clarín, Galdós, Palacio Valdés). ... Pero lo único que fue unánime fue la airada reacción de sus colegas - todos excepto Galdós: viva Galdós! - ante lo que entendieron un acto de presunción y envanecimiento ${ }^{11}$. En realidad en la hostil recepción de las memorias literarias de doña Emilia se sumaban tres negaciones: la que le negaba a ella, como mujer, su derecho a la fama; la que negaba valor artístico al género autobiográfico y ambas negaciones apoyadas, por supuesto, en la negación de reconocimiento de una tradición propia. ¿Alguien puede imaginarse un pozo más hondo?

Bien, la escueta síntesis que acabo de plantearles y sobre cuya realidad parecen caber pocas dudas exige, sin embargo, otra mirada, una mirada más profiláctica, diríamos. Pierre Bourdieu ya consolidó en 1992 la consideración del campo literario como un espacio de convergencia, y conflicto, entre los puntos de vista posibles sobre el hecho literario ${ }^{12}$ (en la sesión de ayer estuve valorando si había algún punto de contacto con el concepto de región literaria defendido por Ricardo Kalima, y creo que sí los hay). En todo caso, la historia crítica de la autobiografía en España, de la que trazo aquí un primer esbozo (y que pienso desarrollar en mi próximo libro gracias a la idea que me han proporcionado, con esta invitación, las profesoras Sissa Jacoby y María Eunice Moreira), nos permitiría descubrir que las negativas tomas de posición sobre el género lo mantuvieron preso de un falso dilema. Solo que variemos nuestra perspectiva de acercamiento comprendemos, de inmediato, que resulta 
absurda la pretensión de descalificar la autobiografía española solo porque en ella no se den las características propias de la autobiografía francesa. En realidad es un punto de partida equivocado (como expuso el profesor Fernando Durán López en su tesis doctoral ${ }^{13}$ ), que inevitablemente conduce a los errores interpretativos que acabo de resumir. Antes de Fernando Durán lo vio con claridad el profesor Francisco Sánchez Blanco, citado asimismo por Durán: "La creencia de que una autobiografía debe responder, de alguna forma, al planteamiento rousseauniano de la interioridad ha sido un obstáculo para la visión hacia otras posibles constituciones del yo que estuvieran en mayor consonancia con la filosofía y la estética entonces existente en España"14.

Visto así, la crítica sobre la falta de intimidad, de sinceridad y de autoanálisis que se ha venido reprochando a la autobiografía española, por contraste con el modelo francés, se deshace como un azucarillo en el café. Es muy posible que la cultura española tenga la autobiografía que puede tener, que ha podido tener, de acuerdo con sus circunstancias, muy distintas de las francesas. Que no disponga en el siglo XVIII de textos al estilo de Las Confesiones no quiere decir que el género se haya desarrollado de una forma "incompleta" o que no haya cumplido con su propia misión. En otras palabras, Las Confesiones de Rousseau no son el Evangelio, es decir no hemos de leerlas como un texto que contiene la verdad universal y revelada del género autobiográfico y por tanto una unidad de medida que debe calzar cualquier tipo de corpus, como si fuera la horma de un zapato. La fe que profesa Philippe Lejeune (por otra parte, el historiador que más ha hecho por el canon de la autobiografía, eso es aparte) en las obras fundacionales de la autobiografía francesa no tiene que ser, necesariamente, compartida a la hora de estudiar la literatura autobiográfica española. En España no se dio la autobiografía al estilo roussoniano, en efecto, porque las características históricas y culturales eran muy distintas. Por ejemplo, la implantación de la Inquisición en 1478 no permitió que el incipiente sujeto autobiográfico que apareció con una fuerza extraordinaria en el Renacimiento español (pensemos en el Libro de la Vida, de Teresa de Jesús; el Diario espiritual de Ignacio de Loyola; el Lazarillo de Tormes...) tuviera continuidad, más que adaptándose a la represiva realidad de la Contrarreforma donde la libre expresión de la conciencia sería dura y cruelmente perseguida. Si para Lejeune la autobiografía es el género por excelencia de la modernidad, que nace con la Ilustración y tiene su texto fundacional, como ya se ha dicho, en Las Confesiones, es tarea inútil adaptar esta concepción del género a la realidad española. De hecho es un planteamiento que excluye la tradición española, tanto cronológica como conceptualmente. En este sentido, y solo en este, podría decirse - y que Dios me lo perdone - que las tesis de Philippe Lejeune han sido un problema, más que una ayuda, al encarar la construcción de un canon literario peninsular, tarea, por cierto, que ha quedado pendiente.

\section{Periodización}

La periodización de la autobiografía en España es muy distinta de la francesa: surge antes y se hunde en el Barroco, justo cuando empieza a brillar en Francia con las memorias de Richelieu, de Saint-Simon, de Mme. de Rolland y tantos otros autores. Para entender la evolución del género en España hay que vincularlo no tanto al autoanálisis, como al arraigado, y si quieren Vds. desdichado, concepto del honor (tan vinculado a la limpieza de sangre) y a sus consecuencias tanto en el ámbito político como moral. Ese honor que tanto fascinaba a escritoras como George Eliott o a la danesa Isaak Dinesen y del que habla, como hemos visto Philarète Chasles. Una de las consecuencias de aquel acusado sentido del honor fue la arrogancia del castellano viejo ${ }^{15}$ concebida como una actitud ante el mundo y como un modo de resolver los muchos conflictos que siempre, y en cualquier edad y época, plantea la vida. En este caso se halla, por ejemplo, el afán de hidalguismo (denunciado de forma magistral por Cervantes a través del Quijote) o bien la jactancia del miles gloriosus, temas recurrentes en nuestra literatura de los Siglos de Oro, personajes que vistos desde una perspectiva biográfica revelan un escaso conocimiento de sí mismos y la afectación de virtudes inexistentes. Si se hubiera conocido algo más a sí mismo el hidalgo muerto de hambre que trata el Lazarillo y que pasa a ser el segundo de sus amos, no hubiera ofrecido una imagen tan lastimosa al perspicaz pícaro. Habría sido capaz de corregir su lamentable catástrofe vital (lo digo en el sentido freudiano) de fundar la vida en un error de apreciación sobre su posición social. El mismo tema plantearía Galdós en una de sus mejores novelas, $L a$ desheredada, que viene a ser una versión femenina del miles gloriosus. Rasgos ambos, el hidalguismo, los sueños de grandeza, que sacaban de quicio a Cervantes, pero que sirvieron de inspiración y soporte a nuestra escritura autobiográfica. Me ciño al ejemplo que proporciona el propio Cervantes en la creación de su Ginés de Pasamonte,

\footnotetext{
13 "La autobiografía moderna en España. Nacimiento y evolución", tesis presentada en la Universidad de Cádiz, 2001. Durán López es autor de numerosas publicaciones vinculadas al rescate de textos autobiográficos anteriores al siglo XIX.

14 En "autobiografía y concepción del "yo" desde Mor de Fuentes a Ramón y Cajal”, en Revista canadiense de Estudios Hispánicos (1987), n. 11, p. 636.

15 Cervantes: "Y este nuestro bárbaro español, en cuya arrogancia debe estar cifrada la valentía del orbe" (Persiles, 597 a). Mariano José de Larra dedicaría asimismo al "castellano viejo" uno de sus sátiras costumbristas más feroces.
} 
un preso condenado a galeras al que don Quijote, a su manera, liberará en la Primera Parte de la novela. Pero antes de hacerlo mantiene con él una conversación en la que el engreído y encadenado Ginés - "Ginés me llamo y Pasamonte es mi alcurnia" - le anuncia con orgullo haber escrito la historia de su vida solo con la ayuda de sus dos pulgares (pues tenía las manos impedidas). Una historia tan buena, dice, que oscurece a cuantas se han escrito hasta entonces, refiriéndose de soslayo y con intención al ya famoso Lázaro de Tormes. No me puedo detener ahora en la interesante situación que plantea Cervantes al equiparar el texto del Lazarillo (una falsa autobiografía) a una de supuestamente verdadera, solo quiero subrayar que el escritor elige al más fantoche de sus personajes para hacerle escribir sus memorias, concibiéndolas pues como un ejercicio de vanidad que solo los hombres más histriónicos, o los más necesitados de "alcurnia", llevaban a cabo.

Esta defensa del honor vinculada tan tempranamente al memorialismo, sufre tres grandes momentos de deflagración vinculados a tres sucesos histórico-políticos de gran calado y que de algún modo lo estaban poniendo en entredicho. He aquí, en mi opinión, una explicación interna de la maltrecha historia de nuestra autobiografía. Veámoslo con más detalle:

1. En primer lugar, la incorporación de las Indias a la corona de Castilla a comienzos del siglo XVI generó un corpus textual de naturaleza memorialística que conocemos como Crónicas de Indias: desde los diarios de Colón a la extravagante relación de Alvar Núñez Cabeza de Vaca, pasando por las cinco Cartas de Relación de Hernán Cortés, dirigidas al emperador Carlos V o la formidable Historia Verdadera de la conquista de la Nueva España, de Bernal Díaz del Castillo ${ }^{16}$, sus autores vinculan el hecho histórico a su experiencia personal y a la defensa de sus intereses:

... (Y) digo otra vez que yo, yo, yo lo digo tantas veces, que yo soy el más antiguo y he servido como muy buen soldado a su majestad y dígolo con tristeza de mi corazón, porque me veo pobre y muy viejo, una hija por casar, y los hijos varones ya grandes y con barbas y otros por criar, y no puedo ir a Castilla. ${ }^{17}$

Bernal Díaz del Castillo advierte, desde Guatemala donde reside en, que no puede ir a Castilla a defender sus intereses y su pasado de miles gloriosus y es por ello

\footnotetext{
$\overline{16}$ Un personaje que ha atraído la atención del antropólogo Maurice Duverger hasta llevarle a pensar, en mi opinión equivocadamente, en Díaz del Castillo como el verdadero y oculto autor de las Cartas de Cortés. Véase mi artículo en ABC Cultural.

17 Cap. CCX, p. 862.

${ }^{18}$ Una idea compartida por el escritor Mauricio Wiesenthal en su magnífico Libro de réquiems (Edhasa, 2004).
}

que escribe su propia historia en la que queda claro que merece un mejor trato del que obtuvo hasta entonces de la Corona. “¿Dónde están nuestros palacios y moradas, y qué blasones tenemos en ellas diferenciadas de los demás (...) y dónde están los sepulcros de los muertos y qué blasones tienen en ellos", se pregunta abiertamente Díaz del Castillo haciéndose eco del malestar de otros soldados que como él vieron defraudadas sus expectativas de gloria y prosperidad. La preocupación que manifiesta Díaz del Castillo sobre la falta de interés de sus compatriotas por la memoria del pasado más reciente, de todos aquellos soldados que murieron en la empresa de la conquista y de los que nadie se acuerda, podríamos conectarla con la que, cientos de años después, expresarán dos escritores alemanes, Ernst Jünger (en El problema de Aladino) y W.G. Sebald (Campo Santo, Anagrama) consternados ambos autores ante la despreocupación del mundo contemporáneo por el pasado que ha dejado de formar parte de su vida: "Recordar a los muertos, conocer sus vidas y recordarlas - escribe Sebald - nos distingue de los animales. Y hasta hace poco la presencia de los antepasados estaba viva en Europa. Ya no."

Ya no. Es una maldición del mundo actual, empeñado en soltar el lastre de cualquier forma de trascendencia hasta dejar desamparados nuestros camposantos ${ }^{18}$. Al paso que vamos, dice Sebald, no quedará nada del pasado, sólo un horizonte hostil y un inmenso mar de indiferencia. Cierto, y Bernal Díaz del Castillo lo vio así antes de 1632.

2. La invasión de la Península Ibérica por parte de tropas francesas a lo largo de 1807 y primeros meses de 1808 constituyó un segundo momento de auge memorialístico. El afán expansionista de Napoleón le condujo a imponer en el trono de España a uno de sus hermanos, quien subió al poder con el nombre de José I. El vacío de poder que se produjo ante la huida de la familia real española culminó con un estallido de ira popular y con la sublevación masiva de gentes de toda España: fue el comienzo de una guerra "total" que duraría seis años (1808-1814) y que supondría un terrible desgaste para el ejército napoleónico. Aquella guerra provocó una deflagración en muchos aspectos de la vida española, pero nos importa subrayar que alteró por completo los usos y las prácticas del Yo desarrolladas hasta aquel momento. Supuso un punto de inflexión en la historia de la autobiografía, que dejó de lado el histrionismo y los delirios de grandeza del pasado, pues los sucesos fueron tantos y de tal intensidad política que muchos de sus protagonistas se vieron después más o menos forzados a escribir el relato de lo sucedido para defender su conducta - el caso paradigmático lo constituyen las Memorias de Manuel Godoy, el hombre más odiado por sus conciudadanos -, o bien Blanco White, con su 
autobiografía en defensa de la libertad religiosa que él mismo practicaba (en Inglaterra).

Aquella avalancha de escritos justificativos hizo exclamar a Larra que...

[L]a invención de la imprenta a la disposición de todo el mundo ha sido un puerto contra el naufragio para generaciones enteras: hecha industria lucrativa, todo el que no ha tenido otro oficio, todo el que se ha creído con ojos para ver, con oídos para oír, todo el que se ha figurado tener las cualidades de testigo (cualidades más difíciles de poseer de lo que parece para no ser testigo a la manera de las paredes, dentro de las cuales pasan los acontecimientos), todo el que ha sentido dentro de sí o la pereza de obrar o la insuficiencia de producir cosas dignas de ser por otros escritas, ha asido de una pluma, y ha exclamado: 'Yo, que no hago nada, escribiré lo que hacen los demás; escribiré lo que sobre ellos pienso, y hasta escribiré lo que yo hago, cuando no hago nada'. De aquí multitud de libros, de novelas históricas, de historias novelescas, de viajes impresionales y de impresiones viajeras que atormentan al mundo moderno y le ahogan y le sofocan, como las demasiadas mantas que se echan sobre un constipado; de aquí la multitud de 'observaciones', 'relaciones', 'reflexiones' y 'ojeadas', sin contar con el sinnúmero de anuncios que empiezan con 'De', como: 'De los acontecimientos de la guerra de tal', 'de la conjuración de cual', 'de la oportunidad', etc., etc.; de aquí ese torrente sin diques de memorias de la contemporánea, del contemporáneo, del ayuda de cámara, del médico, del barbero, del portero, de la mujer, del padre, del hijo, del hermano, del sobrino y de los amigos y de los enemigos del hombre que ha hecho, que ha sonado, que ha intrigado, que ha mandado algo; memorias de su cocinero, de su repostero, de su querida y de su viuda, acerca de la manera que tienen los hombres grandes de ponerse la corbata, de salir a paseo, de dormir, de estar despiertos; memorias de los que le han visto a todas horas, y de los que no le han visto a ninguna. ${ }^{19}$

Larra satiriza el exceso memorialístico que observa entre 1814 y 1836 (cuando escribe su artículo) viéndolo como un factor entorpecedor del verdadero sentido de la Historia: son tantas las voces que tiran de ella en una y otra dirección que hace falta saber nadar muy bien para no ahogarse en el revuelto río de tantos testimonios partidistas. Una crítica que habría que tomar en consideración si no fuera por su evidente carácter retórico: esa introducción hablando del derroche de voces inanes le servirá para subrayar la importancia de la voz de Manuel Godoy, el hombre más odiado de la Historia de España y quien en Paris, abandonado de todos, solo y arruinado, escribe sus Memorias para defender su nombre y el de la familia real. A Larra el testimonio de Godoy le conmovería profundamente y su reseña de las Memorias es una pieza fundamental de la escasa bibliografía crítica suscitada por el género.

Lo cierto es que, por lo general, las memorias justificativas propias de esta etapa suscitaron rechazo y desconfianza. La gente veía la autobiografía, en la forma que la conocía, como un género cargado con la parcialidad de quien escribe para defenderse, para justificar determinadas decisiones políticas o para asegurarse una benévola posteridad, disolviendo los errores en un mar de aciertos. Se asoció de nuevo con la arrogancia más que con la verdad al sospechar de la confesión (por lo general política) como un acto interesado, escrito pro domo sua. Se abría la "guerra de las memorias" entre unos dirigentes y otros, como, de algún modo, la abrió Cervantes con su Ginés de Pasamonte en lucha contra otros relatos de pícaros. Ello explica que cuando un diplomático, en pleno umbral del siglo XX, se sume al aluvión de textos memorialísticos precise lo siguiente:

Ya sé, ya sé que las Memorias constituyen un género anticuado y cursi: por eso las mías son fragmentarias. De lo malo, poco.

Y ni aún fragmentos publicaría de mis Memorias si fueran exclusivamente personales. ¿Qué le importan a nadie los viajes que uno haya hecho, ni las novias que tuvo en la juventud, ni los cuentos que le contaba su venerada abuela? A estos pormenores íntimos se reducen a veces las Memorias de los que cultivan este género de literatura.

Por mi parte, omitiré cuanto sea personalísimo; guardaré para mí solo todo lo concerniente a mi familia, a mi infancia, a mis amores, que profanaría mis más augustos recuerdos haciéndolos pasar por una rotativa. Impresos en el alma, ¿qué impresión más indeleble?

Y para tranquilizar al público, termina: "Tanto o más que de mí hablaré de los demás." 20

"Omitiré cuanto sea personalísimo", dice Nicolás Estévanez, como quien asegura en un libro de poesía que no va a utilizar el verso porque de sobra han escrito utilizándolo. De nuevo nos topamos, sin embargo, con la cuestión capital que tanto ha enturbiado la valoración de la autobiografía en España. Un valor negativo, la falta de libertad de conciencia, se transforma en el XIX (y gracias al auge historiográfico) en un valor positivo: en la idea de que no hay que esperar confesiones de un relato autobiográfico porque el ámbito de la rememoración, por personal que sea, es el relato de lo colectivo y en él debe permanecer la autobiografía, sometiéndose a sus códigos y a sus valores. Pero el lector idebe esperarlas de un texto

\footnotetext{
19 En su reseña a las "Memorias originales del Príncipe de la Paz" (I), El Español, 22/9/1836.

${ }^{20}$ En Mis memorias (1899), de Nicolás Estévanez, Tebas, 1975.
} 
autobiográfico, o no? Así estaban las cosas al comienzo del siglo XX: al memorialismo político con el que arrancó el siglo, le había sucedido el memorialismo literario en el último tercio con obras de Mesonero Romanos, Zorrilla, Julio Nombela, Patricio de la Escosura, Alcalá Galiano, Emilia Pardo Bazán, Armando Palacio Valdés... En conjunto, la explosión autobiográfica anticipada por Larra no trajo sin embargo consigo el sentimiento de que un nuevo mundo había surgido en el siglo XIX, fruto de una incipiente conciencia popular, del desarrollo industrial, de la lucha por la soberanía nacional y del nacimiento de la conciencia obrera. Pero sí sirvió para que surgiera un primer intento de canon literario: lo propuso el erudito alcarreño Manuel Serrano Sanz en 1905: Autobiografias $y$ Memorias constituye el primer intento de reunir lo escrito en el pasado de acuerdo con los criterios de autobiografismo y veracidad. Una obra en dos volúmenes que no serviría para alterar los criterios de la historia literaria de su tiempo.

En otras palabras, el género seguía horro de sus cartas de nobleza, de un texto que se hiciera de lectura imprescindible. Los textos se multiplicaban pero era como si cayeran en una especie de un Mare Tenebrarum del que no conseguían salir a flote.

3. El tercer punto de inflexión en la historia de la autobiografía ocurrió a la muerte de Franco, en noviembre de 1975. La larga censura política y moral impuesta a los españoles sobre lo ocurrido en la guerra civil y el regreso que había supuesto el franquismo a postulados tridentinos, todo eso desapareció de pronto, liberando un cauce autobiográfico verdaderamente sobrecogedor: socialistas, anarquistas, comunistas, republicanos, franquistas, monárquicos, feministas, homosexuales... todos escriben en la Transición para exprimir viejas emociones que han mantenido asombrosamente vivas. Militantes, dirigentes, cabecillas revolucionarios, intelectuales, artistas, exiliados... España, inmediatamente antes y sobre todo después de 1975, tendría prisa por recuperar una memoria amordazada durante cuarenta años y por ello es que hablamos en los años ochenta de un boom memorialístico que no tenía ninguna correspondencia con lo sucedido en otros países europeos. Había una violenta necesidad de reestructurar el pasado reciente, acomodándolo a una verdad histórica y biográfica cuya expresión había sido prohibida. De modo que una nómina importante de autores abrió por fin una vía para el reconocimiento crítico e historiográfico del género: pienso en las Memorias de Carlos Barral, en Coto vedado de Juan Goytisolo, El peso de la paja de Terenci Moix, La vida arrebatada de Lidia Falcón, Pretérito imperfecto de Carlos Castilla del Pino, Desde el amanecer de Rosa Chacel, Travesías de Jaime Salinas o La escritura o la vida de Jorge Semprún, por poner algunos y brillantes ejemplos. Textos que unen a su ambición formal la universalidad y profundidad de sus planteamientos. En común todos tenían la conjunción de un contexto favorable a la libre expresión de la historia de sus vidas. Pero lo más importante es que la sociedad española también lo vio y lo entendió así.

Para Maurice Halbwachs la actividad de restituir el pasado no es posible más que por el hecho de apoyarse en marcos sociales que cada individuo comparte con los otros miembros de su comunidad, aunque lo haga de forma inconsciente. Estos marcos (recuerdos compartidos, textos, monumentos, ritos, testimonios de toda índole) son el soporte de una actividad que el individuo cree realizar por la sola fuerza de su espíritu. Bien, la España postfranquista se vio en la necesidad de rehacer sus marcos sociales e institucionales a fin de dar cabida, como ya he dicho, a una vieja y al mismo tiempo nueva realidad. Y para ello contó por primera vez con la autobiografía. Esta nueva dimensión memorial no ha dejado de crecer y también de resultar conflictiva, pues es objeto de una negociación que pone en juego intereses contrapuestos, generando pasiones colectivas de más o menos amplitud. En todo caso, la publicación de memorias, diarios y correspondencias de ancianos combatientes en el 36 no se ha interrumpido a lo largo de los casi cuarenta años siguientes a la muerte del dictador y es muy probable que no llegue a interrumpirse nunca del todo.

Enrique Vila-Matas en uno de sus últimos libros se imagina un país feliz y alegre que ha dejado de escribir novelas sobre la guerra civil. Pero todos los países tienen sus demonios interiores, sus conflictos a los que vuelven una y otra vez, y lo que importa es enfrentarse a ellos más que soñar con su improbable desaparición.

La autobiografía no es solo una categoría literaria, es también un síntoma, un producto y un reflejo de una época. Se inscribe en un contexto cultural: procede de una configuración ideológica y moral y actúa a su vez sobre la sociedad que la ha segregado.

Para terminar, vuelvo a la cuestión que había planteado inicialmente. Yo había dedicado varios años de mi carrera como investigadora a demostrar que en España existía una tradición autobiográfica con una asombrosa continuidad, pero no reparé sino en fechas recientes que los textos existían, sí, pero no se leían y por tanto no habían logrado formar parte del circuito cultural. Porque al no leerse no generaban ninguna recepción, ni crítica que ayudara a visualizar el género, ni se integraban en la Academia Literaria ni llegaban a las escuelas, ni pasaban a vivir en la mente de los lectores. De modo que aun existiendo, su influencia era nula. Se dudaba de su valor estético y se desconfiaba de su alcance moral. Lectores e historiadores habían hecho oídos sordos a quienes deseaban hacerse escuchar. 
Ahora, la autobiografía es testimonio de la evolución que ha experimentado nuestra sociedad. Se da el caso de que esa nueva y saludable liberación del espacio de lo íntimo se ha visto asaltada en los últimos tiempos por los medios de comunicación que lo manipulan y distorsionan transformando el ansia de verdad en un espantoso simulacro. Pero esa es otra historia. Lo importante es que la autobiografía ha conseguido crear sus propios códigos de lectura y quién sabe si no es ya un refugio activo y lúcido del individuo ante la banalización a la que se nos quiere reducir. Es decir que si un viejo coronel colombiano en los años treinta no tenía quien le escribiera, un memorialista español si tiene ahora quien le lea.

Recebido: 13 de abril de 2014 Aprovado: 07 de junho de 2014

Contato: annacaballe@ub.edu 